\title{
The Endless Reading of Interpretation? Said, Auerbach, and the Exilic Will to Criticism
}

\author{
Guilan Siassi, University of California, Los Angeles
}

In one of his last public appearances less than a year before his death, Edward Said gave a series of four lectures at Cambridge University on the theme of Humanism and Knowledge. ${ }^{1}$ Having outlined the changing bases of humanistic study and called for a 'return to philology,' Said devoted his final talk to 'The Example of Erich Auerbach's Mimesis $^{2}$.' It is no mere coincidence, in Said's view, that Auerbach composed this 'greatest book of general humanistic practice since World War II' (Said 2004, 6) during his Turkish exile from Nazi Germany. The figure of Auerbach as both exemplary literary scholar and precursor of the 'public' intellectual (Said 2004) occupied an important and, it seems, increasingly central place in Said's thought over the course of his career, becoming most visible in the latter's formulation of a new humanism built upon secular criticism and the 'executive value' of intellectual exile. Indeed, if Foucault's systematic archaeology of knowledge influenced various aspects of Said's critical thinking, Auerbach’s humanistic philology informed nearly the whole enterprise of his critical activity.

\footnotetext{
${ }^{1}$ The content of these lectures was recently published under the title Humanism and Democratic Criticism (2004).

${ }^{2}$ In this hallmark of comparative literary history, Auerbach undertakes a systematic study of the 'representation of reality' in a wide array of canonical works from Antiquity to modern times. Approaching each text, from Greek epic to the Old Testament to the Proustian novel, in its original language and with a careful consideration of its broader context, Auerbach demonstrates how narrative representations mediate lived relationships to a particular historical reality. Ultimately, Mimesis serves to show how texts are not only shaped by such historical conditions but also how they encompass interpretive paradigms within which they perform their own idiosyncratic 'readings' of that reality.
}

Portal Journal of Multidisciplinary International Studies Vol. 2, No. 1 January 2005

ISSN: 1449-2490

http://epress.lib.uts.edu.au/journals/portal/splash/ 
Said's concern with humanism as a viable praxis executed in the service of culturally relevant and, indeed, necessary forms of criticism, gives rise to his occasional reservations about Foucault's theoretical project, whose 'circularity,' he fears, leaves little if any room for individual resistance and will. ${ }^{3}$ In contrast, much of his work serves not merely to delineate, catalogue, and archive various régimes du savoir as part of an impersonal network of power relations and anonymous discourse, but to 'reveal the dialectic between individual text or writer and the complex collective formation to which his work is a contribution' (Said 1979, 24). In such projects, Said shows himself to be far less interested in the deconstruction of culture through critical thought than he is, as we will see, in the reconstruction of humanistic values through critical engagement with the world. To this end, he holds up the model of Auerbach to demonstrate how an intellectual must not only unearth cultural artifacts through the reading of texts, but also transform those historical fragments, through an act of synthetic interpretation, into both an artillery for resistance and a tool kit for reparation of the cultural machine. It is in the exercise of a personal 'interpretive art' enabling such cultural recuperation and synthesis that Said brings his own worldly and historical situation, his humanism, and his exilic subjectivity and agency into dialogue with his intellectual forebear.

Perhaps the most appropriate starting point for an inquiry into the nature of Said's transhistorical dialogue with Auerbach is his 1969 translation of the latter's essay, Philology and Weltliteratur, first published seventeen years earlier. As Said points out in his preface, the title of this essay suggests the intersection of humanism and historicism in the domain of comparative literary studies. Auerbach alludes to the

\footnotetext{
${ }^{3}$ Despite his admittedly large debt to Foucault, Said does not hesitate to critique and revise the more cynical aspects of the latter's thought, particularly those emphasizing the inevitable determinism of social life. The divergence of Said's thought from Foucault's theory of authorless production and circulation of knowledge, for instance, is evident throughout his writings; even in as early a text as Orientalism, he affirms that an 'otherwise anonymous collective body of texts constituting a discursive formation like Orientalism' nonetheless carries the determining imprint of individual writers $(1979,23)$. More explicitly, in his essay, 'Travelling Theory,' Said critiques the self-enclosure of Foucault's archeologies, insofar as they 'make not even a nominal
} 
Goethean ideal of a 'world literature' which aims to give expression the common goals and aspirations of humanity, tying this vision to the pedagogical orientation of German Romance philology, whose rigorous methodologies inaugurated the practice of historicism (Auerbach 1969, 1). In this vein, Auerbach advocates a historicist humanism that seeks to penetrate and evaluate Weltliteratur so that an 'inner history... of mankind achieving self-expression'—what he calls ‘our Myth'—could be written (4-5). However, Auerbach is also very much aware of his own historical moment as 'a period of conclusive change' faced with a 'mighty and rapid' process of leveling and concentration that imposes uniformity upon cultures. Though admitting that the new circumstances have made it more difficult than ever to engage meaningfully in a critical activity whose goal is to trace man's 'advance to consciousness of his human condition and to the realization of his given potential' (5), Auerbach does not believe that such humanistic aims have become altogether superfluous in the modern age. Thus, he argues, while such goals should by no means be abandoned, their priority must nonetheless be reconsidered.

When an 'ahistorical system of education' not only threatens to impoverish society but also 'lays claim to dominating us' (6), the philologist's first duty, Auerbach writes, is to counter its representations by revealing our historical contingency and by demonstrating that the history of the present moment determines not only who we are, but also what we can become. Auerbach writes that the Goethean concept of Weltliteratur and its philology, with its vision of 'a spiritual exchange between peoples' (6) is no longer tenable in the modern environment; that any such exchange between cultures not already bound together politically would have little effect on culture or on the 'reconciliation of peoples' as such. In light of these changes, the goal of philology can no longer be a spiritual aim of ‘designating man’s place in the universe,' but only a secular and social one of making men conscious in their own history (16-17).

Advocating this new conception of Weltliteratur as the 'diverse background of a common fate,' and accepting the standardization of world culture as an inevitable fact, 
Auerbach holds that the philologist should facilitate a cultural dialogue between two partners brought together 'in the terminal phases of their fruitful multiplicity,' through political developments. The philologist should render and articulate precisely the 'fateful coalescence' of those two cultures in such a way that the story of their merging will become 'their myth' (7). This account, if anything like the universal, spiritual 'Myth' Auerbach describes earlier in the essay, would also relate 'the research of reality which fills and rules our life' (4).

For the most part, Auerbach remains reticent in his scholarly work about strictly political concerns. Still, the fact that he was a Jewish exile from Germany writing Mimesis at the height of the Holocaust cannot be ignored. As such, the work can be, and has been, read for its broader political implications, for instance, as an engaged response to the crisis of European civilization that culminated in World War II, or more specifically as an interpretation of humanistic realism meant to expose Nazi ideology as legend and thus oppose the literature of totalitarianism. While we may discern in Auerbach's work a general criticism, tinged with nostalgia, of the modern cultural and political state of affairs, and a call (albeit one that remains either implicit or muted in its explicitness) for change, Auerbach himself seems to entertain little hope that his philological activity can have any immediate political impact. In fact, he appears uncertain as to whether this objective - to evoke a political response- should even be the central aim of Weltliteratur and philology at all. That is, on one hand, Auerbach recognizes the need for critical work committed to immediate political objectives, and on the other hand, sees this new critical imperative as a meager auxiliary, and even a degradation of the old Goethean ideal of a philology promoting human spiritual advance. He seems to find a compromise between these worldly and spiritual poles in a humanism that sets interpersonal understanding, cultural exchange, and individual selfawareness within history as its ultimate goal.

Indeed, the closest Auerbach comes to expressing a political agenda is when he acknowledges his aim to achieve 'an insight into the diverse implications of a process

1983, p. 246). 
from which we stem and in which we participate, a definition of our present situation and also perhaps of the possibilities for the immediate future' (quoted in Green 1982, 12). However, stipulating that such an insight could be gained only in the most favorable of circumstances, he goes on to describe not these current-day and future political ramifications of the historical process, but rather a personal reflexivity and self-refinement to which philological criticism gives rise and which, he seems to believe, is its only certain function: 'In any event, such a method compels us to look within ourselves and to set forth our consciousness of ourselves here and now, in all its wealth and limitations’ (12). Thus, although Auerbach acknowledges the broader humanistic import of philology and designates the critic’s work as a task specific to his time, his theoretical reflections do not carry the explicit claim of political agency that we will find, one generation later, in the work of his greatest admirer and champion.

Evoking Auerbach, Said offers a significantly revised view of the critical project in his celebrated essay, 'Secular Criticism.' As Auerbach voiced his disquiet over the processes of 'concentration' and homogenization of culture, Said also begins this essay with a concerned reflection on the practice of high culture in the modern era which, he argues, has been marginal to the serious political concerns of society. Emphasizing the immediate relevance of comparative literary criticism to the exigencies of contemporary social life, he describes the critic as an opponent of the hegemony, an agent of resistance and radical reform 'allied to contesting classes, movements, and values' who produces 'non-coercive knowledge in the interests of human freedom' (Said 1983, 15). Putting into practice this concept of 'secular criticism' in his essays, Said 'affirms the connection between texts and the existential actualities of human life, politics, societies, and events.' It is precisely such 'realities of power and authority-as well as the resistances offered by men, women, and social movements' that, he claims, 'make texts possible, deliver them to their readers, [and] solicit the attention of critics’ (5).

Indebted as he is (despite their differences) to Foucault, Said also holds that any claims about the universal, spiritual value of cultural production and consumption are invalid 
so long as we naïvely view 'the cultural realm and its expertise [as] institutionally divorced from their real connections with power' (2). Said has in mind here the 'camouflaging of the cultural world' facilitated by a kind of High Humanism—from which even the Goethean model is not exempt—-that would exonerate anyone 'cultured' from charges of political corruption and irresponsibility. There is no reason to believe, Said insists, that one who reads and presumably appreciates humanistic literature in the realm of culture — like the Nazi who read Rilke while giving orders of genocide—can not carry out the most anti-humanistic practices, and even become a 'cold-blooded butcher' in the realm of politics (3). In his insistence that the secular critic must mobilize his powers of interpretation as an act of resistance to the hegemonic culture, Said promotes a new humanism to replace the vision propounded in the nineteenth century by imperialists and complicit intellectuals alike. ${ }^{4}$

Said understands culture as 'an environment, process and hegemony in which individuals (in their private circumstances) and their works are embedded' (8). Because culture is consecrated by the State and assimilated to its authority, it is overseen at both the top, by the so-called superstructure, and at the base, by the methodological attitudes governing how individuals may interpret that cultural world or produce new knowledge within it. The power of a state-sanctioned culture, according to Said, lies in its ability to differentiate not only between itself and its 'outside' but also between that which is or is not valuable within itself. Discriminating both within and beyond its domain, the hegemonic culture appropriates 'the entire matrix of meanings we associate with 'home,' belonging, and community' (11). In light of these observations, Said not only resists and challenges a cultural system of values which dominates from above and saturates downward to the material base of society but, in his resistance also refuses the proprietary process involved in 'belonging to' a culture or assuming a cultural identity. It is in the context of this political materiality of culture that he lays out his schema of the possibilities of resistance and agency for the worldly-situated intellectual who engages in secular criticism.

\footnotetext{
${ }^{4}$ Such a vision is perhaps exemplified by Matthew Arnold's Culture and Anarchy, to which Said's Culture and Imperialism has been read as a response.
} 
Said notes that 'in the transmission and persistence of a culture, there is a continual process of reinforcement.' That is, because all forms of discourse rely on the authority of culture, the expression of opinions from a position of power and the translation of those opinions into political acts tend merely to 'validate the culture to itself.' The dominant culture assumes greater authority through its associations with national identity and the state, through its institutions or 'external forms and assertions of itself,' and most importantly, through its 'vindicated power as victor over everything not itself.' Consequently, the state and the related ideological apparatuses to which the power of culture is assimilated, 'tend to be successful in enforcing their hegemony' (1314). But, Said points out, in spite of this rather depressing state of affairs — or perhaps because of it-resistance to cultural pressures by individuals and groups, has been present from time immemorial.

Said provides Macaulay’s Minute of 1835 as an example of a case or cultural precedent by which 'superiority and power are lodged in a rhetoric of belonging, or being 'at home'... and in a rhetoric of administration' (13). In showing how an individual can exploit and re-interpret the authority of culture so as to justify an act of colonial subjugation, Said locates agency in an act of reading (Macaulay’s expressing his 'opinion') situated strategically and instrumentally within the rhetorical power of culture (a locus where ‘opinion' translates into a ‘decision' to act). However, Said implies that this agency is not restricted solely to imperialists whose power derives from the hegemonic culture, its nationalist discourse, and its rhetoric of belonging and 'home.' Rather, the performative speech act, when uttered by any 'individual consciousness placed at a sensitive nodal point' (15), becomes the point of departure, or 'beginning,' from which one executes his or her intentions, critically and methodically, in the world.

Just as the reader begins to wonder by what mechanism the critic can gain access to this decisive point, this position of discursive power, Said reminds us in one evocative word: Auerbach (16). It is no accident that Said's overture to his radical reversal of 
Arnoldian humanism and his revision of Foucauldian cultural criticism is none other than an account of the circumstances under which Mimesis was composed and the 'executive value of exile, which Auerbach was able to turn into effective use' (8). For Said, Auerbach is the icon of exile, a critical consciousness situated in a liminal space. In this figure, he sees a man whose continual discomfort opens up his vision and affords him a certain mobility of thought; a subjectivity which, by virtue of its threshold position, is capable of passing back and forth between two worlds. When Said asserts that distance from his national home made possible Auerbach's undertaking and enabled his 'concrete critical recovery of Europe' (16), he views this possibility of writing differently than Auerbach himself admitted or even imagined. ${ }^{5}$ Said links the writing of Mimesis not just to the physical inaccessibility of a surfeit of material, but to its author's psychological dissociation from the cultural paradigms to which any interpretive act belongs. Said insists that more important than this academic isolation, which allowed Auerbach to write his philological interpretations without inhibition, was his cultural alienation and the corresponding exilic perspective, which permitted him to read literary history anew. Thus, it was exile in the first instance that inspired unique and powerful critical insights and consequently enabled a significant act of cultural recuperation.

Said is intent on showing that the exile's critical recovery of this cultural mythos or 'home' is not only a personal recuperation-a psychic repairing of one's own fractured self-consciousness_-but indeed a concrete political act: an infinitesimal but still meaningful restructuring and reconstruction of the fragmented world. He stresses that the critical consciousness is an isolated voice out of place in its social world 'but very much of that place' and of the literal body it inhabits. Standing for a 'professedly universal or humane set of values' it is 'not by any means an escape' from the world. (Said 1983, 15-16). However, the oppositional critic must straddle the line between

\footnotetext{
${ }^{5}$ Auerbach explains that his exile in Istanbul, which required him to dispense with scholarly materials, may have led to some oversights in his research on the one hand, but that it may just as well have been responsible for the success of his undertaking on the other: 'It is quite possible that the book owes its existence to just this lack of a rich and specialized library. If it had been possible for me to acquaint myself with all the work that has been done on so many subjects, I might never have reached the point of writing' (557).
} 
inside and outside, metropolis and periphery and refuse all binding affiliations that would limit his or her ability to move freely between the two spaces.

He elaborates on the political potential of this 'ascetic code of willed homelessness' in rather specific terms. Far from being restricted to the physically displaced, the exilic perspective depends more on a degree of intellectual ex-centricity acquired through historical knowledge and humanistic learning. Such a 'worldly self-situating' enables 'a sensitive response to the dominant culture' whereby the individual consciousness can introduce 'circumstance and distinction where there had only been conformity and belonging' (15). The individual who stands at a critical distance from the culture troubles the 'quasi-religious authority of being comfortably at home among one's people, supported by known powers and acceptable values, protected against the outside world' (16). In this way, the exilic mode, as JanMohamed points out, is an ambiguous border crossing and a constant shifting back and forth, that elucidates 'the politics of cultural construction of subjects and how the latter can begin to break free from their indigenous formation’ (JanMohamed 1992, 99).

We may couch this notion of exile as a tactical position in neo-Foucauldian language: The intellectual 'subject' of the cultural system depends for his authority upon the power relations governing its regimes du savoir — depends on them even in his opposition to them, in order to be heard as a legitimate dispenser of new knowledge. That is, since the sphere of knowledge to which the intellectual speaks is constituted by the power of culture, any claims falling outside of it would lack authority: Said understands that were he to locate himself definitively outside of this dominant culture, his position would appear, by definition, illegitimate. Thus, by refusing to assume any positive identity in his opposition, by refusing to define himself in any terms other than that of an 'ironic' difference ${ }^{6}$ from the hegemony itself, he remains within the sphere of recognized power and does not forfeit his authority. He can thus mediate,

\footnotetext{
${ }^{6}$ Said describes the irony of a criticism that is constitutively opposed to all reified, totalizing identities in the following terms: 'If criticism is reducible neither to a doctrine nor to a political position on a particular question, and if it is to be in the world and self-aware simultaneously, then its identity is its difference from other cultural activities and from systems of thought or of method.... Criticism is most itself and, if the paradox can be tolerated, most unlike itself at the moment it starts turning into organized dogma' (WTC, 29).
} 
contrapuntally, between the outside and the inside, the metropolis and the periphery, the hegemonic and the subaltern. As Robbins points out, exile in this sense becomes an inversion and redefinition of authority that entails 'a recomposition of cultural capital' (34) and a redistribution of knowledge in the economy of cultural resources.

Still, if Said views exile at the political level, as a potential site of creativity and cultural re-appropriation, he never doubts that at the level of personal experience, it is little more than a 'condition of terminal loss' (Said 2002a, 173). Reading this loss into literary representations and interpretations in The World, the Text, and the Critic, Said further elaborates his dialogical position with respect to Auerbach. In keeping with his view that exile is not only a physical condition but also a state of mind, Said universalizes his personal sense of dispossession; that is, he tacitly compares the loss of home suffered by the exile to a general condition of psychological 'homelessness' in human experience and cultural life in the modern era. He expands on this idea by delineating various 'failures of the generative impulse' (Said 1983, 16), and by critiquing the resultant affiliative modes by which we respond to such filiative loss. In doing so, he offers a response to the critical imperative Auerbach outlines in 'Philology and Weltliteratur': a call for the philologist/critic to trace, preserve, and indeed shapethrough interpretation - the 'inner dream' of mankind as a spectacular production of our historical unraveling. Auerbach’s sense of urgency in this regard is clear:

The loss of such a spectacle-whose appearance is thoroughly dependent on presentation and interpretation-would be an impoverishment for which there can be no possible compensation. To be sure, only those who have not totally sustained this loss would be aware of privation. Even so, we must do everything within our power to prevent so grievous a loss (Auerbach 1969, 5).

Thus, the fear Auerbach articulates here in terms of the loss of this inner dream, Said addresses in terms of another kind of loss: namely that of exile. Indeed, he suggests that the only way to avoid losing this 'spectacle' of our historical becoming is, ironically, to approach it from our own inherent—-though largely unacknowledged or disavowedcondition of exile in the modern world.

Said elaborates this notion of exile as a uniquely modern critical orientation within a schema of dispossession, mourning, and palliative reparation of 'home': the exilic 
perspective is both a symptomatic and a strategic response to the breakdown of what Said calls genealogical bonds of filiation within modernity, a modified world view resulting from such inevitable losses and yet one which allows us to construct in their place surrogate relations of affiliation through which the very meaning of 'home' is redefined. Indeed, modern literary and cultural representations attest to the problematic and universally-fraught nature of such 'vertical' human relationships based on direct genealogical descent and suggest the impossibility of any natural continuity between people ostensibly bound together by patrimony, class, nation, or other fruits of inheritance and 'heritage.' This perceived failure necessitates 'new and different ways of conceiving human relationships’ (Said 1983, 17), and gives rise to a compensatory order of 'horizontal' affiliations, which come in the form of partisan and institutional allegiances, sets of cultural values or religious beliefs, and other ideologies or 'worldvisions' (a negative example of which is Orientalism). Affiliations are constructs of mind which serve as a 'general system of brakes that restrains the always accelerating irrationality of human behavior' (112), putting in check our natural tendency to destroy filiative bonds. ${ }^{7}$

Thus, as an alternative to impossible natural relationships, affiliations substitute social bonds for generational family ties and thus 'preserve the human race... making certain that human history continues by repeating itself according to a certain fixed course of events’ (Said 1983, 112). At the same time, such affiliations allow for intellectual freedom and enable originality, which according to Said is a type of loss in its primal sense (133). Indeed, it is the cooperation between filiation and affiliation, Said asserts, that lies at the heart of critical consciousness (16). The example of Auerbach demonstrates this point: By substituting a relationship of affiliation with the cultural history of Europe for his destroyed sense of filiation with the modern nation of Germany, Auerbach recovered the inner dream of his lost world and reconstituted it as a

\footnotetext{
${ }^{7}$ In his essay, 'On Repetition,' Said makes this point explicit by giving the example of sexual desire and its thwarting by institutions: 'Intentionally, in an unmediated and wholly natural way, filiation gives rise not only to conflict but is driven by a desire to exterminate what has been engendered, the abandonment of offspring. Unintentionally however, [as a result of affiliative constructs], the opposite takes place: marriage as an institution is established, offspring and parents become bound by it' (118).
} 
modern-day ‘myth’ —an interpretation ascribing causal meanings and imparting historical, or at least aesthetic, coherence to a traumatic experience or event. Auerbach's filiative loss and the affiliative alternative he adopted enabled his unique interpretive synthesis: the construction of a narrative relating the 'fateful coalescence' of the worlds and peoples he saw to be approaching the end of their 'fruitful multiplicity.' Directing his critical will to tracing historical processes and sketching patterns without advancing any rigid, totalizing theory, Auerbach could produce a dialectical, dramatic narrative (as opposed to a static vision) of European civilization.

But why is now the time for us to reconsider and learn from the example of Auerbach's Mimesis? Because while affiliation remains the most viable alternative to conceiving human relationships in the modern world, it has also come to pose major problems to the socio-cultural order. Said points out that as natural bonds and forms of authority become transpersonal, affiliation comes to resemble a cultural system with its own hierarchy and totalizing world-view, and 'the process reproduces the filiative discipline supposedly transcended' (Said 1983, 21). In other words, 'for the first time the compensatory affiliative relationships interpreted during the academic course of study in the Western university actually exclude more than they include' (21). This degradation is evidenced by two trends: the critic's coalition with the hegemony of Culture (in the guise of traditional humanism) on one hand, and his betrothal to philosophical, theoretical systems on the other. Both critical systems merely duplicate the tightly knit family structure that secures generational hierarchical relationships and 'succumb to the inherently representative and reproductive relationship between a dominant culture and the domain it rules' (24). With its alliance to cultural dogma that expresses a 'barely sublimated' ethnocentrism and nationalism, and with its ahistorical retreat into textuality, criticism merely perpetuates a 'quasi-religious quietism.' In other words, it becomes 'unworldly.'

In this vein, Said warns us of the irrelevance of criticism to modern social, cultural, and political experience, the danger of its 'enormous complaisance’ in both its public 
affirmation of 'our culture' and in its private unleashing of 'the unrestrained interpretation of a universe defined in advance as the endless misreading of a misinterpretation' (25). Here, Said emphatically asserts his constitutional opposition to such hermeneutical enclosures - what he views as socially irresponsible, antihumanistic modes of reading and interpretation. The example of Mimesis serves to demonstrate an alternative to the blind allegiances of such affiliations, which merely reinstate vestiges of traditional patriarchal authority in a new hermetic system. That is, Auerbach teaches us how an exilic will to criticism — the product of an organic losscan partake in affiliative recuperations of 'home' without falling into the filiative trap.

Said believes that history and literature are not 'inert bodies of experience' but two terms 'mediated by the critical consciousness, the mind of the individual reader and critic,' whose critical agency—namely, interpretation—supplies the 'missing middle term' which connects the two (Said 2002b, 457). Said uses the example of Mimesis as a platform upon which to bring this idea into contrapuntal relief. It is telling that the conceptual thread tying the essays of Mimesis together is Auerbach's view that the 'figural' method of interpretation ${ }^{8}$ formed the basis of realism and left its defining mark on Western literature from earliest times to the modern period. With this thesis, Auerbach not only emphasizes a historicist understanding of literature but, by showing how the conceptual framework of classical antiquity and the interpretive framework of Biblical tradition together determined the kinds of representations produced in European culture, also points out the primacy, in shaping cultural history, of interpretation itself.

Auerbach narrates his synthetic mythos of human history by tracing literary representations of reality — human pasts and presents—as signs pre-figuring their 'fulfillment,' embodying emergent meanings, or bearing a significance to be revealed.

\footnotetext{
${ }^{8}$ This hermeneutical method was based on a form of scriptural exegesis that reached its culmination in the Middle Ages. Projecting an essentially allegorical operation, figural interpretation attempts to decode the hidden moral and anagogical levels of meaning in the Old Testament by reading that text as a pre-figuration of truths contained in the New Testament (i.e. as a foretelling of the Life of Christ, as an elaboration of Christian doctrine, or as an allusion to the larger eschatological promise of the religion as a whole). Figural interpretation is thus the basis for any hermeneutical mode whereby a text is read according to a particular theological or ideological 'master narrative.'
} 
He shows how the dialectical relation of two literary traditions - those of classical antiquity and those of the Old Testament—shaped the representational and hermeneutical aesthetic of his culture. While the former contain 'no secret second meaning,' biblical narratives are mysterious, 'fraught with background.' They thus demand 'investigation and interpretation' and hold out the promise of revealing the 'truth' of the reader's worldly situation, of showing him to be 'an ingredient of the divine plan' (Auerbach 1953, 16). Consequently, a method of interpretation which sees everything that happens in the world as an element in the narrative structure of universal history, could claim absolute authority and spread to other traditions: 'Interpretation in a determined direction becomes a general method of comprehending reality' (16). This idea, the Ansatspunkt, as it seems, of Auerbach’s philological undertaking, has further implications: that cultural development is intricately tied to schematic hermeneutical conceptions or 'readings'; and that more importantly, it is bound to a general critical will. In other words, Auerbach shows how a particular style of representation evolved in response to an existing will to interpretation —one which sought to make immanent the meanings it believed latent in worldly history. Thus, the concept of figura was in essence Auerbach's re-reading of a history of interpretation as represented in realistic literature.

Auerbach writes that the 'order and the interpretation of life' is to be discerned in the thoughts, consciousness, and 'in a more concealed form,' in the words and actions of individuals:

For there is always going on within us a process of formulation and interpretation whose subject matter is our own self. We are constantly endeavoring to give meaning and order to our lives in the past, the present, and the future, to our surroundings, the world in which we live; with the result that our lives appear in our own conception as total entitities—which to be sure are always changing.... (Auerbach 1953, 549).

The overlapping, complementing, and contradictions of such formulations of the world 'yield something that we might call a synthesized cosmic view or at least a challenge to the reader’s will to interpretive synthesis’ (Auerbach 1953, 549). Though subject to revision and expansion, such an act of interpretive synthesis reflects one's unique critical style and is in this sense a 'personal art' in its own right: a product of personal 
intuition which carries nonetheless the possibility of 'centrifugal radiation' from the 'circumscribed set of phenomena' it comprehends (Auerbach 1969, 15). It is in this way that the critic writes a history-from-within against a broader background-a myth that is at once enduring, unified, and perhaps even universal.

It is this emphasis on interpretation in Auerbach's philology that seems to have influenced Said most as he undertook his own readings of 'Western' history and culture. Indeed, at the most fundamental level, Said's Orientalism is an account of how a will to interpretation (primarily religious and political) set in motion a self-perpetuating cycle of 'Orientalist' representations. But in contrast to Auerbach, whose interpretation of literary representations and historical events traced the cultural development of Europe in terms of its inherited identity (Greco-Roman and Judeo-Christian), Said' synthetic analysis traces this development in terms of its exploited alterity (Oriental and Muslim). Thus, through a contrapuntal reading from his own exilic perspective, Said offers an alternative description of a world 'unified in its multiplicity,' a counter-narrative of what Auerbach calls the ‘inner history’ of Western culture.

Weaving his own notion of loss into the fabric of dialogical critique, Said further expands and revises his forebear's instructions for advancing humanistic goals through critical engagement in the world. For Said, the 'inner dream of mankind' unfolding in literary representations of human experience, is to be interpreted by the well-trained critic as a collective consciousness not only sedimented in historical time but also scattered throughout exilic space.

My interest in Auerbach's method... unlocked the system of correspondences between history and literature that is the cornerstone of a whole tradition regarding temporality as both the repository of human experience... as well as the mode of understanding by which historical reality can be comprehended (Said 2002b, 457).

But while Auerbach’s philological activity was based on a temporal approach, Said affirms that a hermeneutical technique mapping the movements and migrations of representational discourse - a literary topography —is now equally necessary. That is, the 'system of correspondences' Said describes above can be gleaned through an interpretive mode of mediating time or-and this becomes the emphasis of exilic 
criticism—a mode of mediating space. Indeed, though an interpretive discipline grounded in temporality is still essential, in the age of globalization, spatiality must be regarded as a substantial 'repository of human experience' and hermeneutical mode by which we can comprehend historical reality as well.

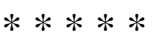

Said opens his 'Introduction' to the fiftieth-anniversary edition of Mimesis with the following quote from Gabriel Garcia Marquez:

...human beings are not born once and for all on the day their mothers give birth to them, but that life obliges them to give birth to themselves.

This epigraph in many ways summarizes the intersection of Said's reading of Auerbach, his concept of filiation and affiliation, and his notion of exilic criticism. It suggests that writing, both creative and critical, is a perpetual accouchement-a 'kind of self-making within the context of the specific dynamics of society at a very precise moment in its development' (Said 2003, xiii). For Said, Auerbach serves as a model of the critic situated psychologically and intersubjectively in the world, who like Said himself, enacts the personal drama of being expelled from 'home' and of his endless quest to make a new home for himself_-or rather, to remake himself within the rented space of his writing - through cultural critique. It is thus that the relationship of Said, the readercritic, with Auerbach's text and indeed with Auerbach-as-text becomes a 'sympathetic dialogue of two spirits across ages and cultures’ (xiv).

Within this transhistorical exchange, the dialectical shifting in cultural space between filiative and affiliative processes that Said delineates in modern culture is comparableand in many ways a response - to the backwards and forwards oscillation of literary representations in historical time that Auerbach plots in Mimesis. Said sees these representations as the mediatory methods and optics through which individuals, situated in a particular cultural space and historical moment, view and articulate reality. Moreover, he asserts, whether they take the form of creative writings or interpretive readings, they play an important role in shaping human history and society: 
The 'representation' of reality is taken by Auerbach to mean an active dramatic presentation of how each author actually realizes, brings characters to life, and clarifies his or her own world.... [Auerbach], in turn re-realizes and interprets and, in his unassuming way, even seems to be staging the transmutation of a coarse reality into language and new life (Said 2003, xx).

Can we not see this transmutation as an effort to recuperate the loss of his filiative home and redeem it for a more broadly human affiliation with the world? As Said writes, Mimesis is the emblem of such a 'recuperative and redemptive human project,' through which Auerbach could reconstruct the history of his own time (Said 2003, xxxi).

It is, Said emphatically affirms, the impossibility of finding a home-either in inherited filiations or adopted affiliations - that leads one to remain precariously wedged in marginal spaces and to assume a critical perspective between 'culture and system.'

Like Auerbach, he aspires to resemble the ‘perfect man’ of Hugo of St. Victor, one who finds virtue in changing 'invisible and transitory things’-worldly attachments, filiations and affiliations — only to thereupon 'leave them behind altogether.' (Said 2002, 185). It is this homelessness, this orphanhood, that Said believes, leads the exilic writer to construct in his text a temporary shelter - a house that is conducive to perpetual self-creation and personal growth. But, when the exilic writer finally reaches this 'perfect' state of seeing the entire world 'as a foreign land,' a 'need to rewrite and redo' renders his text 'uninhabitable' and reveals his situation to be, ironically, all the more appropriate. Quoting Adorno, Said points out, 'In the end, the writer is not even allowed to live in his writing.' Clearly, more than the 'proprietary solidity of permanent ownership,' Said values this sense of the 'provisional and contingent' -an inconclusiveness which, he concludes, is nonetheless preferable to the 'sleep of selfsatisfaction and the finality of death' (Said 2002c, 568).

Had Auerbach not been driven from his German home in 1935, would he have felt the same urgency to reread the cultural history of Western civilization? Had Said not been forced to leave the land to which some of Auerbach's fellow exiles laid claim, would he have gained access to the exilic space and critical perspective from which he could do the same? Obviously, this is a rhetorical question. But in the answers we carve into its blank spaces, against the backdrop of its hypothetical time, we may perhaps findalbeit for only a fleeting moment—our own historical and cultural 'homes.' 


\section{Reference List}

Auerbach, E. (1953), Mimesis: The Representation of Reality in Western Literature, Princeton University Press, Princeton.

-(1969), Philology and Weltiteratur. The Centennial Review, XIII (Winter), 117.

Green, G. (1982), Literary Criticism and the Structures of History: Erich Auerbach and Leo Spitzer, University of Nebraska Press, Lincoln.

JanMohamed, A. R. (1992), Worldniness-without-World, Homelessness-as-Home:

Toward a Definition of the Specular Border Intellectual, In Edward Said: a critical reader, ed. M. Sprinker, Blackwell, Oxford and Cambridge Mass.

Robbins, B. (1994), Secularism, Elitism, Progress and Other Transgressions: On Edward Said's 'Voyage,' Social Text, 40 (Autumn), 25-37.

Said, E. W. (1979) Orientalism, Vintage Books, New York. (1983), The World, the Text, and the Critic, Harvard University Press, Cambridge.

(2002a), Reflections on Exile, in Reflections on Exile and other Essays, ed. E.W. Said, Harvard University Press, Cambridge, Mass, 173-186.

(2002b) History, Literature, and Geography, in Reflections on Exile and other Essays, ed. E.W. Said, Harvard University Press, Cambridge, Mass, 453-473. (2002c), Between Worlds, in Reflections on Exile and other Essays, ed. E.W. Said, Harvard University Press, Cambridge, Mass, 554-568.

(2003), Introduction to the Fiftieth-Anniversary Edition of Mimesis, ed. E Auerbach, Princeton University Press, Princeton, x-xxxii.

(2004) Humanism and Democratic Criticism, Columbia University Press, New York. 